\title{
Formação continuada e pós-graduação: introito retrospectivo do Serviço Social
}

\author{
Continued background and pos-graduate: retrospective initial of the Social Service
}

\author{
Nilsen Aparecida Vieira Marcondes* \\ Juliana Alves Barbosa** \\ Elisa Maria Andrade Brisola***
}

\begin{abstract}
Resumo:
O assistente social na busca de efetivação das suas competências profissionais depara-se com a necessidade constante de atualizar-se, pois a amplitude e as dimensões que envolvem seu campo de intervenção demandam isso dele. A inexistência de dicotomia entre a natureza teórica e prática do Serviço Social reforça a importância desta análise. Portanto, sob o respaldo da Teoria Social Crítica, objetiva-se com este estudo contribuir para que as discussões em torno da formação continuada e consequentemente do exercício profissional constituamse como centro das discussões. A análise bibliográfica, ora empreendida, materializa-se numa produção qualitativa e exploratória, ancorada na revisão da literatura sobre o tema Formação Continuada e Política Nacional de PósGraduação sob o enfoque do Serviço Social. A perspectiva analítica empreendida neste estudo permite apontar que, a questão da formação continuada e da PósGraduação, entremeadas pela conjuntura neoliberal, deve ser reforçada reiteradas vezes por parte de uma categoria profissional que busca constante sintonia com as alterações evolutivas que se verificam no interior da sociedade capitalista.
\end{abstract}

Palavras-chave: Pós-graduação. Formação continuada. Serviço social.

\begin{abstract}
:
The social worker in seeking fulfillment of their professional skills is faced with the constant need to update themselves, because the size and dimensions involving the operating environment demand it of him. The lack of dichotomy between the theoretical and practice of Social reinforces the importance of this analysis. Therefore, under the umbrella of Critical Social Theory, the objective of this study was to contribute to the discussions around the continuing education of
\end{abstract}

\footnotetext{
* Universidade de Taubaté/SP - UNITAU. Assistente Social da Prefeitura Municipal de São José dos Campos e Mestranda do Programa Acadêmico e Interdisciplinar em Desenvolvimento Humano: Formação, Políticas e Práticas Sociais da Universidade de Taubaté/SP.E-mail: nilsenmarcondes@gmail.com.

** Universidade de Taubaté - UNITAU. Assistente Social da Prefeitura Municipal de Pindamonhangaba e Mestranda do Programa Acadêmico e Interdisciplinar em Desenvolvimento Humano: Formação, Políticas e Práticas Sociais da Universidade de Taubaté/SP. E-mail: juliana-alvesbarbosa@hotmail.com.

*** Universidade de Taubaté - UNITAU. Assistente Social, Doutora em Serviço Social pela PUC-SP, Chefe de Departamento de Serviço Social da Universidade de Taubaté e Docente do Programa Acadêmico e Interdisciplinar em Desenvolvimento Humano: Formação, Políticas e Práticas Sociais da Universidade de Taubaté/SP.E-mail: elisabrisola@uol.com.br.
} 
professional practice and therefore constitute itself as the center of discussions. The literature review undertaken now materialized into a production and exploratory qualitative, grounded in the literature review on the topic Continuing Education and the National Graduate from the standpoint of Social Work. The analytical approach taken in this study allows us to point out that the issue of continuing education and graduate, interspersed by neoliberal conjuncture, should be reinforced repeatedly by a professional category that seeks constant harmony with the evolutionary changes that occur within of capitalist society.

Keywords: Pos-graduate. Continued background. Social service.

\title{
Introdução
}

A vida em sociedade move-se no interior de um processo extremamente dinâmico. Uma característica que desponta é sua "natureza social, distinta da natureza física e de seus elementos decodificadores, [estando desse modo] sujeita a múltiplas variáveis demarcadas pelo campo difuso das relações societárias e multiculturais". Com isso, verifica-se que "o social é sempre uma construção, portanto é grafado pela relação espaço tempo [onde] todo conhecimento é perene até que um novo conhecimento demonstre sua falência." (SPOSATI, 2007, p. 17). Esta constatação, portanto revela a importância da formação continuada.

\begin{abstract}
O interesse pelo tema da formação continuada difundiu-se nos últimos anos, envolvendo [...] pesquisadores, acadêmicos, educadores e associações profissionais. Há uma grande mobilização em torno do assunto, a produção teórica é crescente, eventos oficiais e não oficiais propiciam debates e razoável circulação de análises e propostas [...] Observa-se que a formação continuada tem recebido atenção de destaque (GATTI; BARRETTO, 2009, p. 199).
\end{abstract}

As entidades organizativas da categoria como o Conselho Federal de Serviço Social (CFESS) e a Associação Brasileira de Ensino e Pesquisa em Serviço Social (ABEPSS) são unânimes na defesa da importância da formação continuada, creditando a tal realização a possibilidade de efetivar-se como contributo para "garantia da materialidade efetiva [da] profissão [na medida em que] atualiza e forma um profissional sintonizado com as exigências da época, quando a velocidade das transformações dificulta os momentos de síntese." (NOGUEIRA, 2005, p. 187-189). 
Apesar de a discussão ser contínua e apresentar processo evolutivo considerável, esta tendência não é acompanhada por uma conceituação unívoca do termo, o que é saudável porque as demandas por formação continuada variam conforme necessidades profissionais individuais e coletivas, bem como contexto e tipo DE ação realizada. Além disso, a característica ontológica do termo formação continuada também apresenta nuances, conforme expressam as autoras Gatti e Barretto (2009, p. 200):

[...] a designação de formação continuada [...] cobre um universo bastante heterogêneo de atividades, cuja natureza varia, desde formas mais institucionalizadas, que outorgam certificados com duração prevista e organização formal, até iniciativas menos formais que têm o propósito de contribuir para o desenvolvimento profissional [...], ocupando [ou não] as horas de trabalho [...], ou se efetivando como trocas entre pares, grupos de estudo e reflexão $[\ldots]$.

Bourdieu (1989 apud GONÇALVES; LISBOA, 2007, p. 88) busca afirmar suas conviç̧ões a respeito da importância da "noção de trajetória [compreendida como] uma série de posições sucessivamente ocupadas por um mesmo agente - ou mesmo grupo em um espaço, ele próprio em devir e submetido a transformações incessantes". Portanto, partindo-se da concordância com essa afirmação e por entender que ela dá margens para se justificar e reforçar a necessidade da formação continuada como multifacetada e contínua no decorrer da vida profissional, defende-se que em se tratando de formação continuada:

[...] o conceito subjacente é o de desenvolvimento profissional. O processo de formação é definido como um movimento orientado a responder aos diversos desafios que se sucedem [nas] diferentes fases da vida profissional: o início da carreira, o processo de desenvolvimento e os tempos mais avançados em que o [profissional] consolida sua experiência [...] (GATTI; BARRETTO, 2009, p. 203).

Acrescenta-se a isso o fato da própria natureza da profissão também apresentar vicissitudes, que por si só justificam a formação continuada, pois as construções de conhecimentos bem como perspectivas teóricas sofrem influências de diversos "modos de apreensão do real, que tem por base uma concepção de mundo, na qual o [profissional] se apóia [destacando-se] o positivismo, a fenomenologia, o materialismo dialético [enfim]" (LARA, 2007, p. 77). 
Pelo exposto, infere-se, portanto, o quanto a formação continuada amolda-se à realidade do Serviço Social enquanto profissão "complexa, diferenciada, e historicamente [susceptível a influência] de determinados modos de pensamento [configurando-se desde o] pensamento social da igreja, [passando pelo] pensamento funcionalista [até chegar nos dias de] hoje ao pensamento marxista" (NOGUEIRA, 2005, p. 191).

Ainda com relação à herança cultural sob a qual o Serviço Social vem fundamentando sua prática e consequentemente um contínuo repensar na questão da formação continuada, tem-se a seguinte síntese de lamamoto (2011, p. 27-28; p. 211212):

\begin{abstract}
Em seus primórdios, o Serviço Social estabeleceu uma interlocução privilegiada com o pensamento social católico e com o pensamento conservador europeu, tendo se secularizado em estreita aproximação com as concepções estruturalfuncionalistas difundidas nas Ciências Sociais e Humanas norte-americanas, além da incorporação de rudimentos da Psicanálise. A aproximação teórica da profissão ao universo diferenciado da tradição marxista ocorre tardiamente, a partir de meados dos anos 60, na América Latina, no bojo do conhecido "movimento de reconceituação do Serviço Social". Instaura-se, a partir de então, uma tendência ao debate plural no campo das idéias no meio acadêmico do Serviço Social. [...] Na década de 80, sob o impulso das lutas políticas na defesa da democracia e dos direitos sociais, afirma-se a maioridade acadêmica dos assistentes sociais impulsionada pela pós-graduação, pelo crescimento do mercado editorial e por uma fértil produção acadêmica [...] (grifo da autora).
\end{abstract}

Considera-se ainda que a formação continuada além de trazer em seu bojo "a perspectiva do acumulo do conhecimento [desdobra-se também no] partilhamento [e] transmissibilidade desse conhecimento [o que] implica na capacidade de construir novos sentidos contextuais" (SPOSATI, 2007, p. 24) e assim "gestar conhecimentos que acrescentem subsídios teórico-metodológicos, coerentes [...] com as exigências societárias" (BOURGUIGNON, 2007, p. 49).

A formação continuada instrumentaliza o assistente social na tarefa de sistematização da realidade social, sendo justamente tal sistematização o contributo para um agir mais seguro e mais propenso a emitir respostas mais adequadas aos dilemas impostos. Portanto, para os profissionais de Serviço Social

[...] que pretendem ser críticos e propositivos no atual cenário nacional [...] é fundamental compreender [que] o processo de produção de conhecimento [constitui] elemento de transformação da realidade social pela mediação do 
trabalho, reconhecendo o conhecimento como uma das expressões da práxis [...] para através das possibilidades de respostas atender às necessidades do homem em suas dimensões individual e coletiva [e isso] porque faz parte da natureza da profissão desvendar a complexidade do real e nele buscar as possibilidades de intervenção (BOURGUIGNON, 2007, p. 49).

Pela mediação do trabalho, compreende-se que a formação continuada, enquanto possibilitadora de aquisição de novos conhecimentos, ganha centralidade ao mesmo tempo em que amplia seu potencial de enfrentamento das "contradições e desafios presentes no contexto [sócio-histórico] instigando a profissão permanentemente a sua superação" (BOURGUIGNON, 2007, p. 50), o que é muito importante porque "[...] o assistente social é responsável, na condição de sujeito, pelo desempenho dos papéis de ator e autor da história; tem responsabilidades pelo ser e pelo vir a ser do Serviço Social." (SETUBAL, 2007, p. 68).

Portanto, a formação continuada quando pensada no contexto da Pós-Graduação "deve responder à necessidade de atualização de profissionais graduados, [para que sejam] capazes de articular com agilidade e eficiência os conhecimentos gerados pela pesquisa científica e aqueles gerados pelo exercício profissional." (YAZBEK; SILVA, 2005, p. 38).

\section{O Serviço Social na busca de legitimidade pela via da pós-graduação}

A busca por reconhecimento e espaço no contexto da Pós-Graduação representou uma conquista para o Serviço Social. Conquista porque a inclusão na programação das agências financiadoras de pesquisa foi demorada até mesmo para a própria Ciências Humanas. Para o Serviço Social, a inclusão foi ainda mais letárgica porque este não contava com o reconhecimento nem mesmo por parte das Ciências Humanas, apesar de estar inserido dentro delas. Acrescenta-se a isso o fato de que, para o Serviço Social, a questão foi um pouco pior em decorrência da sua "especificidade e seu modo de inserção na divisão sócio-técnica de trabalho, houve uma tendência entre os pesquisadores, mesmo no âmbito das Ciências Sociais, a considerá-lo uma disciplina de aplicação, de caráter interventivo e não de pesquisa." (BAPTISTA; RODRIGUES, 1992, p. 127).

É importante ressaltar que as Ciências Sociais são reconhecidas no contexto das agências de fomento à pesquisa no Brasil somente na década de 1970. Anterior a essa 
data, elas se encontravam ausentes. Durante as décadas seguintes, de 1980 e 1990, por conta dessa inserção começou a ver um reconhecimento e consolidação de uma identidade profissional. Entretanto, o Serviço Social ainda se encontrava dissociado dessa realidade porque,

[...] apesar de fazer parte da área das Ciências Sociais Aplicadas, apesar da concessão de bolsas para alunos de Pós-Graduação nos anos 1970, só passou a receber auxílio de pesquisa na década de 1980 e, mesmo assim, de forma reduzida, uma vez que, em 1987, as agências financiadoras passaram a contemplar apenas doutores, numa área de conhecimento ainda em construção, com poucos titulados nesse nível (SILVA et al., 2005, p. 73).

Ainda com relação à questão da inclusão tardia na programação das agências financiadoras de pesquisa por parte do Serviço Social, tem-se que

[...] existem fatores internos à profissão que dificultaram (e ainda dificultam) tanto uma valoração mais objetiva da pesquisa e do investimento científico necessários à sua expansão e desenvolvimento, quanto o reconhecimento do Serviço Social como área que não pode prescindir da pesquisa [...] (BAPTISTA; RODRIGUES, 1992, p. 127).

Dentre os fatores citados acima pelas referidas autoras, estão a demora na inserção da disciplina de pesquisa no currículo do Serviço Social, fato ocorrido somente em 1982, embora algumas escolas a possuíssem, a disciplina não era obrigatória antes desta data; insuficiência de um ensino que capacitasse com qualidade os alunos dos cursos de PósGraduação; definição de temas de pesquisa que não possuem consonância com as necessidades da profissão; ausência de entendimento claro sobre o que significa investigação e intervenção; e, "apropriação equivocada de conhecimentos [...] da teoria marxista, que redundou em equívocos teórico-metodológicos." (BAPTISTA; RODRIGUES, 1992, p. 127-128).

Portanto, "a expansão da produção do conhecimento à época [1970] relaciona-se ao caráter emergente da pesquisa na área das Ciências Sociais, às dificuldades de ordem ideológicas, ao questionamento da cientificidade da área e aos preconceitos contra o próprio cientista social." (NOGUEIRA, 2005, p. 191).

Na década de 1990, a área de Ciências Sociais e, inserida nela, o Serviço Social já tinham sido reconhecidos. Alcançando "certa legitimidade [...] as agências financiadoras 
se mostravam mais sensíveis e passavam a valorizar os objetos de investigação e as temáticas abordadas pelo serviço social". O financiamento dos projetos de pesquisa em Serviço Social é muito importante porque "são inúmeros os problemas sociais cujo conhecimento aprofundado são essenciais para a ação dos assistentes sociais" (BAPTISTA; RODRIGUES, 1992, p. 130-131).

Nos dias atuais, verifica-se que o Serviço Social na busca por legitimidade, dentro da Pós-Graduação, trilha por caminhos de crescimento e amadurecimento. Essa trajetória é expressa pela "ampliação de convênios com instituições nacionais e internacionais, aumento da produção intelectual -, com destaque à produção técnica - e a tendência de expansão e fortalecimento dos grupos/núcleos de pesquisa" (IAMOMOTO, 2011, p. 456).

Acrescenta-se também que, em decorrência desta corrida por legitimação, constata-se no interior das universidades o predomínio de um "corpo docente composto [...] por doutores, vários com pós-doutorado no Brasil e no exterior, sendo que a maioria dos programas [de Pós-Graduação] dispõe de veículos próprios de divulgação da produção científica (Revistas e Cadernos)" (IAMAMOTO, 2011, p. 456).

[...] a principal base da produção de conhecimento e da investigação no Serviço Social brasileiro [encontra-se] prioritariamente alicerçada na pós-graduação, com núcleos de pesquisa consolidados, [entretanto] constata-se, hoje, a efetiva presença da investigação no ensino de graduação e de valorização da pesquisa no exercício profissional. [E] a concentração temática da pesquisa indica uma profissão com profunda vocação histórica, atenta aos cenários das transformações operadas na relação entre o Estado e a sociedade no país, no marco das relações internacionais [...] (IAMAMOTO, 2011, p. 456, 459).

\section{Construindo uma trajetória}

O primeiro curso de Serviço Social no Brasil surgiu em maio de 1936 na Pontifícia Universidade Católica de São Paulo - PUC/SP, e, segundo Nogueira (2005, p. 191), os Programas de Pós-Graduação a partir da década de 1970, quando concomitantemente estava sendo iniciada a primeira reforma do ensino universitário brasileiro.

O agravamento da questão social no período da ditadura somado às complicadas "relações entre Estado, sociedade em mercado no pós 64 [...] obrigaram o Serviço Social a procurar aporte nas Ciências Humanas e Sociais, qualificando-se como um parceiro 
intelectual e também protagonista da produção e pesquisa social no Brasil." (MOTA, 2005, p. 12).

Em 1972, iniciam-se as atividades do primeiro Curso de Mestrado em Serviço Social da Pontifícia Universidade Católica do Rio de Janeiro (PUC/RJ) e no mesmo ano na Pontifícia Universidade Católica de São Paulo (PUC/SP). Na sequência, outras Universidades em diversos estados brasileiros também instituíram o Mestrado. E passados dez anos, na PUC-SP, no ano de 1981, foi instituído o Curso de Doutorado em Serviço Social. Na ocasião era o único curso de doutorado na América Latina e em língua portuguesa (BAPTISTA; RODRIGUES, 1992, p. 111; YAZBEK; SILVA, 2005, p. 44).

Portanto, verifica-se que a produção do conhecimento avolumou-se a partir da década de 1970, estando diretamente relacionada ao surgimento dos primeiros cursos de Pós-Graduação na área das Ciências Sociais e em Serviço Social. Desta feita, é de se assinalar o crescimento considerável da literatura pertinente à área, mediante elaborações de dissertações de mestrado e teses de doutorado (LARA, 2007, p. 76; MOTA, 2005, p. 12; NOGUEIRA, 2005, p. 191; YAZBEK; SILVA, 2005, p. 29).

[...] a Pós-Graduação stricto sensu em Serviço Social [foi] impulsionada por professores e profissionais motivados pelo ideal de desenvolver a vida acadêmica, a produção científica e a prática profissional com fundamentos teórico-metodológicos também construídos no interior do exercício acadêmico e profissional. Foi [também] uma expressão de rompimento com a postura positivista que determinava a separação do pensar e do agir; do construir conhecimento, do intervir na realidade social (YAZBEK; SILVA, 2005, p. 42).

Segundo Simionato (2004 apud SILVA et al., 2005, p. 73):

[...] o conhecimento produzido nos Programas de Pós-Graduação, a partir dos anos 70, permitiu a incorporação do pensamento crítico que sustentou, nos anos de 1980, a construção de um novo projeto profissional. A apropriação do pensamento dos autores clássicos das Ciências Sociais sustentou a recriação da capacidade de análise, de interpretar e de intervir no real do Serviço Social, que emergia como área de conhecimento.

Os assistentes sociais começaram a se organizar em torno dos Programas de PósGraduação que "se constituíram em espaços férteis e essenciais para que ocorresse o desenvolvimento do conhecimento na área" (NOGUEIRA, 2005, p. 191). E não foi por acaso que tenha sido uma das profissões precursoras 
[...] a responder à política nacional de modernização das Universidades brasileiras iniciada na década anterior [afinal] estava em jogo [...] seu acesso a um estatuto no mundo acadêmico que o levava a investir com força na formação científica não apenas de seus professores, mas também de um corpo de pesquisadores que contribuíssem para a construção de conhecimentos, com legitimidade científica, na área (BAPTISTA; RODRIGUES, 1992, p. 111-112).

Não obstante aos fatos históricos ocorridos em 1971 e em 1981, o Serviço Social somente consegue ganhar espaço dentro da área de Ciências Sociais a partir de 1984, sendo que em 1986 torna-se integrante do Comitê de Psicologia Social e Serviço Social. E, até 1992, a participação do Serviço Social era considerada "muito pouco significativa ao nível de demandas [...] perdendo [na ocasião] apenas para a Demografia, a Geografia e o Planejamento Urbano." (BAPTISTA; RODRIGUES, 1992, p. 127).

[...] somente a partir dos anos de 1980 [é] que o Serviço Social obteve reconhecimento pelo CNPq como uma área específica de pesquisa, sendo-lhe atribuídas as seguintes linhas de investigação: Fundamentos do Serviço Social, Serviço Social Aplicado, Serviço Social do Trabalho, Serviço Social da Educação, Serviço Social do Menor, Serviço Social da Saúde e Serviço Social da Habitação. Atualmente o Serviço Social integra, juntamente com as áreas de Direito, Comunicação, Economia, Administração, Arquitetura, Demografia e Economia Doméstica, a grande área de Ciências Sociais Aplicadas (LARA, 2007, p. 76).

O currículo mínimo do Serviço Social foi firmado em 1982, sendo consolidado em 1996 e aprimorado em 1999. De lá para cá, a formação continuada dos profissionais tem sido um desafio permanente, pauta de preocupação constante do Conselho Federal de Serviço Social (CFESS) e da Associação Brasileira de Ensino e Pesquisa em Serviço Social (ABEPSS), principalmente após os anos 1980, quando se considera que a profissão amadureceu muito intelectualmente (NOGUEIRA, 2005, p. 190).

No ano de 1988, no Rio de Janeiro, quando foi realizado o I Encontro de Programas de Pós-Graduação, promovido na época pela Associação Brasileira de Escolas de Serviço Social (ABESS), atualmente ABEPSS, ficou decidido "que os programas de pós-graduação stricto sensu deveriam privilegiar a formação de docentes e pesquisadores enquanto que a pós-graduação lato sensu deveria se voltar para a formação de especialistas". Assim, "as primeiras produções de dissertações de mestrado começaram a surgir a partir de 1974 [e] 
as primeiras teses de doutorado foram apresentadas a partir de 1986" (BAPTISTA; RODRIGUES, 1992, p. 121, 123-124).

A ABEPSS tem promovido a cada dois anos o Encontro Nacional de Pesquisadores de Serviço Social - ENPESS. E, em decorrência do adensamento da pesquisa nos últimos 30 anos, estes Encontros acabam por se configurar como espaços de articulação, de capacitação e realização de debate político-acadêmico. O que é muito importante, pois contribuiu para que o Serviço Social possa cada vez mais se qualificar como área produtora de conhecimento socialmente relevante.

Essa maioridade intelectual fez com que o Serviço Social fosse reconhecido como produtor de conhecimento na área das Ciências Sociais Aplicadas por parte do Conselho Nacional de Desenvolvimento Científico e Tecnológico (CNPq) e também pela Coordenação de Aperfeiçoamento de Pessoal de Nível Superior (CAPES). Ambos os reconhecimentos incentivaram na direção do aprimoramento crescente da pesquisa acadêmica e produção bibliográfica (SILVA et al., 2005, p. 73).

A dimensão investigativa perpassa todos os níveis da formação profissional seja na Graduação e Pós-Graduação, e como o Serviço Social possui em sua própria natureza, em sua própria constituição, o aspecto interventivo, a pesquisa vem então complementar este aspecto da profissão mantendo uma relação bem estreita com essa natureza da profissão.

É inegável que a produção na área do Serviço Social teve um impulso considerável após a implantação dos programas de pós-graduação [...] a partir da década de 70. Essa produção teve força suficiente para justificar a criação de uma editora que [...] publicava preferencialmente a produção dos assistentes sociais - a Cortez Editora [e] os corpos docente e discente dos programas de pós-graduação [...] viabilizaram a criação da revista quadrimestral Serviço Social \& Sociedade [...] desde 1979. Alguns programas de pós-graduação criaram, no âmbito de suas Universidades, revistas para divulgação dos trabalhos desenvolvidos [...] (BAPTISTA; RODRIGUES, 1992, p. 123).

Como seria de se esperar, um forte impulso, no que tange à organização à e sistematização do conhecimento em Serviço Social, é consequência também da criação dos veículos de divulgação. A importância e presença destes meios de comunicação impressos e nas décadas seguintes também on-line configuraram-se como estímulo à produção de um conhecimento pautado tanto num crescente 
[...] rigor teórico, histórico, e metodológico da realidade social e do Serviço Social, como [na] ampliação de conhecimentos sobre os processos sociais contemporâneos, que implicam a constituição e o desenvolvimento do capitalismo, do Estado, da sociedade civil, do trabalho, da pobreza, da exclusão, da democracia, da cidadania, das Políticas Sociais e do Serviço Social (SILVA et al., 2005, p. 75).

Entretanto, é importante também considerar que, não obstante, produção bibliográfica relevante expressa em artigos de periódicos, capítulos de livros, livros integrais, editorias de revistas dentre outros, a participação em eventos científicos como conferência, comunicação, painel, mesa-redonda, enfim, e a constituição, organização e fortalecimento de grupos e núcleos de pesquisa igualmente representaram valiosa iniciativa para organização, sistematização e divulgação do conhecimento produzido pelo Serviço Social.

Nas décadas de 1980 e 1990, paralelamente à lógica da contrarreforma do Ensino Superior no Brasil, o período marca "historicamente avanços e conquistas para o Serviço Social nos seus diferentes campos de ação, bem como em seu processo de constituir-se e de consolidar-se como espaço de produção de conhecimento." (BOURGUIGNON, 2007, p. 47).

A Pós-Graduação assumiu papel fundamental na superação [do] viés positivista que marcou o Serviço Social, contribuindo largamente para capacitar os profissionais também enquanto cientistas sociais preocupados em mudar a realidade social opressora e produzir conhecimento sobre essa realidade para embasar a prática profissional e contribuir para avanço científico das Ciências Sociais (YAZBEK; SILVA E SILVA, 2005, p. 42).

No período entre 1994 e 1996, foram elaboradas as diretrizes curriculares do Serviço Social e posteriormente submetidas à análise do Conselho Nacional de Educação. O contexto na ocasião era de nova reforma do ensino superior, trazendo consequências não somente à profissão do assistente social, mas também a todas as demais profissões em âmbito público nacional.

As consequências dessa reforma para o Serviço Social esbarram no próprio projeto de formação, na medida em que compreende os sujeitos como "cidadãos críticos" e 
defende uma atuação profissional pautada na "defesa da democracia, a igualdade, da consolidação de direitos econômicos, políticos e sociais [...]." (FERREIRA, 2004, p. 94).

Portanto, esses objetivos do projeto de formação encontram-se desalinhados "com algumas das orientações da reforma do ensino superior" no Brasil, das quais se pode destacar: ênfase acentuada na educação como mercadoria, desconsiderando-a como direito social a ser garantido; estímulo às formações específicas em contraposição das formações generalistas; priorização da quantidade e não da qualidade; e, instauração de processos avaliativos como instrumentos de competitividade entre instituições, cursos e entre pares profissionais (FERREIRA, 2004, p. 94).

Verifica-se então que a "fragmentação e a pulverização da formação profissional colocam em risco o processo histórico e coletivo de construção de um projeto de profissão ligado a um projeto de sociedade". Com isso caminha-se para a instalação de uma visível "contradição entre a proposta de formação das diretrizes curriculares e a proposta de formação subjacente à reforma do ensino superior", o que compromete "a formação e o exercício profissional crítico, na perspectiva de transformação societária" (FERREIRA, 2004, p. 95).

O projeto de profissão do Serviço Social também "se confronta com a perspectiva governamental de formação profissional predominantemente preparatória para o mercado", voltada "para atender às necessidades e interesses do capital." Com isso, "a formação e o exercício profissional correm o risco de sujeitar-se à ditadura do mercado" (FERREIRA, 2004, p. 95). Na categoria profissional, é consensual a identificação de uma discordância quanto ao fato da "universidade [...] ser reduzida a meros centros de transmissão de conhecimentos e formadora de profissionais para atender ao mercado de trabalho." (SILVA et al., 2005, p. 72).

\footnotetext{
Esse mundo globalizado, além de contextualizar o desenvolvimento científico [...] fornece contornos sociais e organizacionais em que o conhecimento assume papel de destaque. Dessa forma, as inovações e os processos tecnológicos passam a ser condição de desenvolvimento econômico, e este, o condicionador da própria produção do conhecimento. Assim, instaura-se um novo modo de produção do conhecimento, marcado especialmente pela parceria entre universidades e empresas, onde as vantagens e os ganhos comerciais são a "pedra de toque" do desenvolvimento científico-tecnológico [...] Esse novo modo de produção do conhecimento, típico de um projeto societário global centrado no processo de acumulação da riqueza para alguns e
} 
na opressão e exploração de muitos, acontece no âmbito da articulação entre Estado, universidade e empresa (SILVA et al., 2005, p. 70, grifo da autora).

Conclui-se, portanto que o ethos do neoliberalismo tem impregnado o Programa de Pós-Graduação. Oficialmente essa presença se verifica no período que compreende 2005 até os dias atuais. Fala-se de 2005 porque data deste período o marco legal que instituiu - IV Plano Nacional de Pós-Graduação, polarizando as tendências conservadoras do projeto neoliberal. No entanto, a primeira reforma universitária ocorreu em 1968, desencadeando-se mais acentuadamente posteriormente na década de 1980 e prosseguindo acompanhada pela reforma do Estado na primeira metade da década de 1990. Portanto, extraoficialmente a influência neoliberal vem se apresentando mais precisamente desde o momento da consolidação da democracia no país (PAULO NETTO, 2004, p. 11-33).

[...] as principais medidas governamentais para a realização de reformas educacionais são resultantes de interferências do Banco Mundial nos rumos de nosso desenvolvimento e particularmente na formulação das políticas educacionais em curso. Estas interferências caracterizam-se pela "prevalência da lógica financeira sobre a lógica social e educacional; pela falácia de políticas que declaram o objetivo de elevação da qualidade de ensino [...]" (YAZBEK; SILVA, 2005, p. 35, grifo da autora).

As relações entre ciência e sociedade tangenciam a construção do conhecimento e a formação continuada. Esta constatação não é nova, tendo sido clássico o debate que incide sobre a ciência e o conhecimento enquanto vetores que promovem "a liberação ou opressão humana [onde] questões vinculadas à produção do conhecimento e sobre o papel desse conhecimento na sociedade contemporânea [...]" ganham centralidade nas discussões (SILVA et al., 2005, p. 70).

Tal constatação histórica coloca em relevo a urgência de se refletir sobre os objetivos dos Programas de Pós-Graduação de modo que se possa adequá-los, tornandoos respostas mais eficientes e eficazes aos problemas sociais decorrentes do modelo de desenvolvimento adotado no Brasil. E isso é possível porque tanto a "produção do conhecimento [quanto] seu destino depende das ações e das decisões de hoje. Nessa perspectiva, recoloca-se o conhecimento como elemento fundamental na construção dos destinos da humanidade [...]" (SILVA et al., 2005, p. 71). 
[...] precisamos ter uma política de formação que articule graduação e pósgraduação e processos de capacitação e atualização permanentes. Neste conjunto, o eixo de sustentação deve assentar-se nas demandas e nos impasses vivenciados pelos profissionais no contexto do exercício da profissão, considerando as determinações sociais, econômicas, políticas e culturais que expressam a realidade contemporânea e o projeto ético-político profissional (BOURGUIGNON, 2007, p. 53).

Como o assistente social "[...] atua na transversalidade das múltiplas expressões da questão social, da defesa dos direitos sociais e humanos e das Políticas Públicas que os materializam" (SILVA et al., 2005, p. 75), o desafio intelectual que se apresenta é o de que a produção do conhecimento esteja:

[...] fundada em um processo de competência técnica, criativa e crítica, [requerendo um] método científico e rigor filosófico, além da precisão técnica. A competência crítica implica a postura cognoscitiva que permite entender que a produção do conhecimento vai muito além da relação sujeito/objeto, que envolve a trama das relações socioeconômicas e culturais e permite o distanciamento tanto do absolutismo dogmático como do ceticismo vulgar. Finalmente, a criatividade tem a ver com atitude. Além de tudo isso, requer o reconhecimento que os produtos do conhecimento são bens de toda a humanidade e, assim devem ser usufruídos por todos (SILVA et al., 2005, p. 7172).

Ademais, outro desafio que emerge no trato da temática formação continuada

[...] é a necessidade de se [...] pensar o Serviço Social na sua articulação PósGraduação/Graduação, com a sociedade brasileira e com a construção do conhecimento, tendo como desafio a produção de saberes que [...] contribuam para o fortalecimento das lutas sociais, na construção de uma sociedade democrática, tendo em vista a repartição da riqueza socialmente produzida, a inserção social de todos e a construção de um padrão de vida digna e socialmente aceitável. Isso coloca o Serviço Social no âmbito de um movimento contra-hegemônico, na busca de enfraquecer a hegemonia do projeto neoliberal [...] (CARVALHO; SILVA, 2005, p. 135-136).

Portanto, em que pese os desafios citados e as evidências dos influxos neoliberais presentes no Programa de Pós-Graduação; no âmbito do Serviço Social, considera-se que tal Programa possui especial importância

na qualificação e no avanço do Projeto Ético-Profissional [...], hegemônico, no Brasil, desde [...] 1980 [...] fazendo avançar a formação profissional, a 
interlocução com a realidade social e a produção do conhecimento no âmbito da profissão e das Ciências Sociais (CARVALHO; SILVA, 2005, p. 137).

\section{Aprimoramento profissional: uma necessidade constante}

Os assistentes sociais "assumem a produção do conhecimento como possível contribuição da profissão para compreensão e solução de problemas sociais que afetam a grande maioria da população brasileira." (SILVA et al., 2005, p. 72). Partindo desse entendimento, comunga-se da fala de Nogueira (2005, p. 186), ao afirmar que existe "uma grande procura pela qualificação profissional, mantendo-se altos os níveis de matrícula nos cursos de pós-graduação". Portanto, a consequência disso é que:

[...] pela Pós-Graduação, o Serviço Social ganhou espaço junto ao CNPQ, à CAPES e a outras agências de fomento. O pós-doutorado e a livre docência podem ser realizados no país ou no exterior. $O$ volume e a qualidade dessa produção revelam uma profissão que alcançou sua maturidade intelectual (YAZBEK; SILVA, 2005, p. 30).

A formação continuada na sua dimensão teleológica condensa realidades amplas constituídas por uma diversidade e uma heterogeneidade de aspectos que permite ao profissional de Serviço Social, que se vê envolvido numa realidade dinâmica em contínua transformação, considerar os diferentes momentos históricos e o movimento das diversas forças que incidem sobre sua atuação prática cotidiana, agregando maior qualidade à sua intervenção.

Não se pode falar em formação continuada sem levar em consideração a produção de conhecimento que alimenta a prática cotidiana do assistente social, caso contrário não se tem como subsidiar uma ação "socialmente relevante, capaz de garantir um desempenho profissional de qualidade, que se contraponha à precariedade, ao aligeiramento e ao produtivismo [...]." (ASSOCIAÇÃO BRASILEIRA DE ENSINO E PESQUISA EM SERVIÇO SOCIAL, 2011, p. 8).

O dinamismo da sociedade caminha paralelamente aos processos de transição que Ihe são inerentes e são tais processos que determinam as novas necessidades de formação continuada para os profissionais, novos assuntos a serem trabalhados e focados. Além disso, o próprio Serviço Social também sofre modificações, atualiza-se junto com a sociedade, pois esta última representa seu espaço privilegiado de ação. 
Esta característica mutável do Serviço Social, além de ser conseqüência do meio social, é também dos condicionantes históricos oriundos de determinados modos de pensamento. Para ilustrar isso, Baptista (1992, p. 88) é esclarecedora:

\begin{abstract}
Houve um momento [...] em que o pensamento social da igreja católica foi dominante, o que não significou [...] que outros modos de pensamentos - tão como o funcionalismo norte-americano - não convivessem com este, mas sim que o modo de pensar da igreja determinava novos conteúdos e novas características àqueles outros modos de pensar. Em outro momento, a situação se inverteu e tivemos a dominação do pensamento funcionalista com a permanência da perspectiva doutrinária, mas [...] na condição de subordinada aos requisitos daquele [...] Hoje podemos dizer que temos, no serviço social, a hegemonia de um pensamento forjado na tradição marxista. No entanto, isto não quer dizer que o Serviço Social brasileiro [...] seja [...] predominantemente marxista $[\ldots$ e] que a maior parte dos assistentes sociais se posicionem como marxistas [...] (BAPTISTA, 1992, p. 88).
\end{abstract}

Os profissionais estão envolvidos com as mais diversas práticas e a formação continuada de que necessitam muitas vezes se particulariza conforme a atuação concreta realizada. E isso ocorre porque, apesar do assistente social estar diante de realidades comuns a outros profissionais, sua ação possui uma dimensão interventiva, existindo de sua parte uma "preocupação com a incidência do saber [adquirido] sobre a sua prática [pois, no] Serviço Social, o saber crítico aponta para o saber fazer crítico" (BAPTISTA, 1992, p. 88-89).

\begin{abstract}
Nos diferentes espaços ocupacionais do assistente social é de suma importância impulsionar pesquisas e projetos que favoreçam o conhecimento do modo de vida e de trabalho [...] O conhecimento poderá alimentar ações inovadoras, capazes de propiciar o atendimento às efetivas necessidades sociais dos segmentos subalternizados [e] esse conhecimento é pré-requisito para impulsionar a consciência crítica e uma cultura pública democrática (IAMAMOTO, 2011, p. 200).
\end{abstract}

Por conseguinte, "abrem-se enormes possibilidades de estudo e ação para uma disciplina interventiva, como o Serviço Social, os quais vão exigir necessariamente um esforço significativo de capacitação teórica, investigação e técnico-operacional." (FAUSTO NETO, 1992, p. 97). Com isso, a necessidade de respaldar a atuação profissional com a formação continuada, fornecendo-lhe inclusive nova direção torna-se muito oportuna, necessária e atual. 
Compreende-se, portanto, o quão importante é a presença da formação continuada na vida profissional do assistente social, uma vez que são seus conhecimentos adquiridos e continuamente reciclados que irão direcionar os caminhos pelos quais sua ação irá trilhar na superação da característica de cotidianidade que sua prática assume. $\mathrm{E}$ isso é muito necessário porque em face de:

[...] questões imediatas, a estrutura de objetividade da sociedade impõe freqüentemente comportamentos de manipulação do aparente que, na continuidade da ação, devem ser superados, dando lugar a projetos de intervenção cuja intencionalidade ultrapasse o imediato, tendo em vista mudanças mais profundas na situação, objeto da intervenção (BAPTISTA, 1992, p. 90).

O investimento na formação continuada, que além de promover a qualificação profissional, agrega também qualidade na prestação dos serviços, requer a preparação de "[...] um profissional imbuído de um olhar e de uma lógica de ação crítico-investigativa" (FAUSTO NETO, 1992, p. 98) porque "toda a prática, mesmo a mais utilitária e cotidiana, contém em si uma referência à consciência, uma vez que a intencionalidade precede objetiva e cronologicamente a intervenção." (BAPTISTA, 1992, p. 90).

A formação continuada pode contribuir enquanto possibilitadora de superação dos determinantes que se põem na cotidianidade. Nesta direção, ela representa uma poderosa aliada ao profissional que diariamente se vê envolvido com questões que expressam os "modos de relações sociais capitalistas [como] o relacionamento reificado, o atendimento às necessidades básicas transformado em mercadoria [...]." (BAPTISTA, 1992, p. 90).

Como a prática de trabalho do assistente social está envolvida com realidades particulares vivenciadas por indivíduos, famílias, grupos e setores populares sobre os quais se refletem as questões relacionadas à divisão de classes, o profissional é chamado a inserir-se em contextos particulares e universais. E para tal desafio, necessita de formação continuada tanto no âmbito "teórico-metodológico para ler a realidade e atribuir visibilidade aos fios que integram o singular no coletivo quanto o conhecimento do modo de vida, de trabalho e expressões culturais desses sujeitos sociais [...]." (IAMAMOTO, 2011, p. 231). 
O fato de o Serviço Social constituir-se numa profissão traz inerente uma exigência de ação na sociedade, o que não exclui a possibilidade e a necessidade de dedicar-se a investigações e pesquisas no amplo campo das ciências sociais e da teoria social [...] contribuindo para o crescimento do patrimônio científico das Ciências Humanas e Sociais (grifo da autora).

A ausência de uma formação continuada dificulta a realização de uma prática que ultrapasse o limite da realidade focada na intervenção. Com isso se quer reforçar que a formação continuada determina a forma de apreensão do real, e que na atuação prática do profissional está implícita a bagagem teórico-metodológica de que dispõe para intervir na sua realidade local de trabalho.

E essa apreensão do real é muito importante para o profissional porque:

[...] consiste em investigações dos processos sociais nos quais o Serviço Social intervém [...] tendo em vista interpretá-los em termos de sua inter-relação dinâmica com os processos amplos de relações de uma sociedade específica. Nessa relação, com o desvelamento das múltiplas determinações que os concretizam, o caráter histórico desses processos vai tomando significado (BAPTISTA; RODRIGUES, 1992, p. 132).

E ainda,

[...] quando o assistente social está frente ao real e pretende fazer dele uma leitura e, a partir dela, uma intervenção mais aprofundada, via de regra se ressente de falta de instrumentalização. $O$ problema da defasagem teóricoprática dos profissionais, principalmente ao nível de sua intervenção, precisa ser enfrentado (BAPTISTA, 1992, p. 93).

Vive-se numa época em que é requisitado do assistente social uma atuação a nível macro, por isso sua inserção na sociedade requer a ultrapassagem do âmbito institucional, local ou territorial. Porém, sabe-se que para isso precisa de qualificação, de formação e ainda continuada porque a dinâmica social é transformada a todo instante. $E$ essas transformações econômicas e políticas da sociedade repercutem diretamente e de maneira bastante incisiva na atuação prática desenvolvida.

Do profissional é exigido

[...] domínio de conhecimentos para realizar diagnósticos socioeconômicos de municípios, para leitura e análise de orçamentos públicos, identificando seus alvos e compromissos, assim como os recursos disponíveis para projetar ações; o domínio do processo de planejamento; a competência no gerenciamento e 
avaliação de programas e projetos sociais; a capacidade de negociação, o conhecimento e o know-how na área de recursos humanos e relações no trabalho, [...] possibilidades de trabalhos nos níveis de assessoria e consultoria, [...] requisições no campo da pesquisa, de estudos e planejamento [...] (IAMAMOTO, 2011, p. 207).

Como muitas vezes o que se sobressai na atuação do assistente social é seu aspecto imediatista, efetivado pelas respostas que continuamente é chamado a dar às questões emergentes do cotidiano, pode-se ter a ideia de que o profissional parte sempre de soluções provisórias e focadas somente naquela realidade particular.

Não obstante a questão da formação continuada não representar um alento eficaz no enfrentamento da malfadada questão social, seu descrédito por outro lado levaria a um reforço do processo de alienação a que se é submetido dentro do sistema capitalista. Sabe-se que somente a competência cognitiva por mais valorosa que seja não representa solução eficaz para o enfrentamento da questão social se não for acompanhada de uma intervenção prática condizente.

Portanto, a necessidade de formação continuada deve se apresentar na atualidade como possibilitadora de uma análise mais rigorosa da realidade, bem como desencadeadora de uma intervenção viabilizadora de direitos de cidadania.

\section{Considerações Finais}

Uma análise conclusiva, baseada em estudos comparados de diversos autores, permite considerar que a realidade do ensino superior no Brasil teve o setor privado ampliado em comparação com o setor público. Isso evidencia uma política governamental de favorecimento e incentivo da rápida expansão da educação privada. Com isso, a educação deixa de ser direito social e passa a ser vista e encarada como mercadoria.

[...] trata-se de mudanças que atingem a concepção da educação como direito social e imprimem a esta o significado de mercadoria e de serviço a ser vendido e explorado no mercado [...] A produção do conhecimento e saber autônomo e crítico fica [...] comprometida, diante dos imperativos de produção para responder às demandas do mercado de trabalho e de produção de capitais (FERREIRA, 2004, p. 89).

Por consequência, o que se tem hoje é uma "leitura do ensino superior" pautada na lógica do mercado, em que as variáveis que prevalecem são "custo/benefício, 
eficácia/inoperância e produtividade." (IAMAMOTO, 2004, p. 40). E, com isso, assiste-se cada vez mais ao "estreitamento de laços da universidade com o mundo empresarial - no financiamento de pesquisas, laboratórios, bolsas de estudos, convênios para prestação de serviços etc. [...]" (IAMAMOTO, 2004, p. 50).

Não obstante a possibilidade de existência de elementos de avanço presentes na Política Educacional em curso, estes acabam por se diluir dentro de um projeto que possui uma direção global regressiva, liberal e conservadora. Diante desse contexto, é importante não se deixar levar pelo encantamento e pelas promessas que se apresentam com as vestes de modernidade, com a indumentária de inovação (BEHRING, 2004, p. 99).

Compreender que a situação instalada no sistema educacional é consequência de opções políticas dos últimos governos significa dizer que os problemas não serão resolvidos no contexto da educação, mas sim por meio de mudanças na realidade política brasileira (PAULO NETTO, 2004, p. 26, 33). E ainda, é preciso ter clareza também de que

[...] a educação, como espaço específico, porém não exclusivo de formação, ao configurar-se como política pública e direito do cidadão padece, igualmente, das orientações reducionistas e privatizadoras que assolam as demais políticas públicas neste momento (FERREIRA, 2004, p. 81-82).

$\mathrm{Na}$ atualidade, o ensino superior ainda se apresenta condicionado a lógica do custo/benefício, e ainda traz consigo marcas "[...] da profunda crise contemporânea do capital". Hoje, o país é caracterizado "pela constituição de uma universidade heterônoma, ou seja, que historicamente reforçou as relações de dependência, no contexto de desenvolvimento desigual e combinado da economia capitalista". Tal situação se reflete "na produção do conhecimento e na formação profissional em todos os níveis [...]" (BEHRING, 2010, p. 1,).

[...] o [sistema capitalista] tende a deslocar direitos sociais, entre os quais a educação superior, para o setor de prestação de serviços definido pelo mercado, segundo os critérios de produtividade, competição e eficiência, desfigurando-a, ao tempo em que comprime o espaço público e amplia o espaço privado (IAMAMOTO, 2011, p. 438, grifo da autora).

Portanto, é urgente, entender a educação como direito, o que não representa impeditivo para uma "convivência democrática com o ensino privado, partindo da 
compreensão de que este presta um serviço público, o que requer das instituições privadas projetos pedagógicos de qualidade [...]" (BEHRING, 2004, p. 101).

\section{Referências}

ASSOCIAÇÃO BRASILEIRA DE ENSINO E PESQUISA EM SERVIÇO SOCIAL. Estatuto da Associação. Brasília, 2008.

BAPTISTA, M. V. A produção do conhecimento social contemporâneo e sua ênfase no Serviço Social. Cadernos ABESS-CEDEPSS, São Paulo, n. 5, p. 84-95, maio 1992.

BAPTISTA, M. V.; RODRIGUES, M. L. A formação pós-graduada - Stricto Sensu - em serviço social: papel da pós-graduação na formação profissional e desenvolvimento do Serviço Social. Cadernos ABESS-CEDEPSS, São Paulo, n. 5, p. 108-134, maio 1992.

BEHRING, E. R. Carta convite. In: ENCONTRO NACIONAL DE PESQUISADORES EM SERVIÇO SOCIAL - ENPESS, 12., 2010, Rio de Janeiro, 2010.

Implicações da reforma do ensino superior para o exercício profissional do assistente social: desafios para o CFESS. Revista Temporalis, Goiás, v. 1, n. 1, p. 11-33, jul. 2004.

BOURGUIGNON, J. A. A particularidade histórica da pesquisa no Serviço Social. Revista Katálysis, Florianópolis, v. 10, p. 46-54, 2007.

CARVALHO, D. B. B.; SILVA, M. O. S. Conclusão. In: . (Org.). Serviço social, pósgraduação e produção de conhecimento no Brasil. São Paulo: Cortez, 2005. p. 133-138.

FAUSTO NETO, A. M. Q. "Taller" de investigação e projetos sociais. Cadernos ABESSCEDEPSS, São Paulo, n. 5, p. 96-107, maio 1992.

FERREIRA, I. B. Implicações da reforma do ensino superior para a formação do assistente social: desafios para a ABEPSS. Revista Temporalis, Goiás, v. 1, n. 1, p. 81-97, jul. 2004.

GATTI, B. A.; BARRETO, E. S. S. Professores do Brasil: impasses e desafios. Brasília: Unesco, 2009.

GONÇALVES, R. C.; LISBOA, T. K. Sobre o método da história oral em sua modalidade trajetórias de vida. Revista Katálysis, Florianópolis, v. 10, p. 83-92, 2007.

IAMAMOTO, M. V. Reforma do ensino superior e serviço social. Revista Temporalis, Goiás, v. 1, n. 1, p. 35-79, jul. 2004. Serviço social em tempo de capital fetiche. São Paulo: Cortez, 2011.

LARA, R. Pesquisa e serviço social: da concepção burguesa de ciências sociais à perspectiva ontológica. Revista Katálysis, Florianópolis, v. 10, p. 73-82, 2007. 
MOTA, A. E. Prefácio. In: CARVALHO, D. B. B.; SILVA, M. O. S.(Org.). Serviço Social, PósGraduação e Produção de Conhecimento no Brasil. São Paulo: Cortez, 2005. p. 11-16.

NOGUEIRA, V. M. R. Intervenção profissional: legitimidades em debate. Revista Katálysis, Florianópolis, v. 8, n. 2, p. 185-192, jul./dez. 2005.

PAULO NETTO, J. Reforma do estado e impactos no ensino superior. Revista Temporalis, Goiás, v. 1, n. 1, p. 11-33, jul. 2004.

SETUBAL, A. A. Desafios à pesquisa no serviço social: da formação acadêmica à prática profissional. Revista Katálysis, Florianópolis, v. 10, p. 64-72, 2007.

SILVA, M. O. S. et al. A pesquisa, a produção e a divulgação de conhecimento dos programas de pós-graduação na área de serviço social. In: CARVALHO, D. B. B.; SILVA, M. O. S. (Org.). Serviço social, pós-graduação e produção de conhecimento no Brasil. São Paulo: Cortez, 2005. p. 69-131.

SPOSATI, A. Pesquisa e produção de conhecimento no campo do serviço social. Revista Katálysis, Florianópolis, v. 10, p. 15-25, 2007.

YAZBEK, M. C.; SILVA, M. O. S. Das origens à atualidade da profissão: a construção da pósgraduação em serviço social no Brasil. In: CARVALHO, D. B. B.; SILVA, M. O. S. (Org.). Serviço social, pós-graduação e produção de conhecimento no Brasil. São Paulo: Cortez, 2005. p. 25-49. 